\title{
Light slow-down in semiconductor waveguides due to population pulsations
}

\author{
Mørk, Jesper; Kjær, Rasmus; Poel, Mike van der; Yvind, Kresten
}

Published in:

CLEO/Europe-EQEC 2005 Conference Digest CD

Link to article, DOI:

10.1109/EQEC.2005.1567190

Publication date:

2005

Document Version

Publisher's PDF, also known as Version of record

Link back to DTU Orbit

Citation (APA):

Mørk, J., Kjær, R., Poel, M. V. D., \& Yvind, K. (2005). Light slow-down in semiconductor waveguides due to population pulsations. In CLEO/Europe-EQEC 2005 Conference Digest CD: Europhysics Conference Abstracts (Vol. vol. 29B, pp. EA3-5-WED). IEEE. https://doi.org/10.1109/EQEC.2005.1567190

\section{General rights}

Copyright and moral rights for the publications made accessible in the public portal are retained by the authors and/or other copyright owners and it is a condition of accessing publications that users recognise and abide by the legal requirements associated with these rights.

- Users may download and print one copy of any publication from the public portal for the purpose of private study or research.

- You may not further distribute the material or use it for any profit-making activity or commercial gain

- You may freely distribute the URL identifying the publication in the public portal 


\title{
Light slow-down in semiconductor waveguides due to population pulsations
}

\author{
Jesper Mфrk, Rasmus Kjar, Mike van der Poel, and Kresten Yvind \\ Research Center COM, Techn. Univ. of Denmark, Bld. 345v, DK-2800 Kgs. Lyngby, Denmark, jm@com.dtu.dk
}

There is currently a large interest in applying fundamental discoveries on slow light for practical applications, e.g. buffering and storage of light [1]. While the first demonstrations of light slow-down were performed in ultra-cold atomic gasses using the physical effect of electromagnetically-induced transparency, recent experiments were performed in a ruby crystal at room temperature [2], based on the effect of coherent population oscillations (CPO). In this paper we analyze theoretically the prospect of inducing light-slow down in a semiconductor waveguide based on CPO and present experimental observations of the effect.

Fig. 1 (top) shows numerical calculations of the effective group refractive index, $n_{g}$, experienced by a probe beam in the presence of a pump for an absorbing semiconductor medium. Due to wave-mixing mediated by carrier-density pulsations, the probe experiences strong dispersion, which leads to the shown detuningdependence of $n_{g}$. The result depends on the gain-index coupling ( $\alpha$-parameter), except for zero detuning, where the result can be simply interpreted in terms of absorption saturation. The negative values for the group index correspond to superluminal propagation and were also obtained in Ruby [2]. Fig. 1 (bottom) shows $n_{g}$ averaged over the length of a $100 \mu \mathrm{m}$ waveguide, when propagation effects are included. Due to absorption saturation, the induced change of $n_{g}$ depends nonlinearly on the input intensity, $P_{i n}$.

Experimentally, the group index change induced in a reverse-biased semiconductor waveguide $(\mathrm{L}=100 \mu \mathrm{m})$ is measured by employing a sideband modulation technique [2]. The temporal delay, $\Delta t$, is measured relative to a frequency reference by using a network analyzer and is converted to a group index change, $\Delta n_{g}=c \Delta t / L$. Fig. 2 shows the measured $\Delta n_{g}$ values as function of reverse bias and input power. As the reverse bias is increased, the absorption of the waveguide increases and at the same time, due to carrier sweep-out, the carrier lifetime is reduced, reaching a value as low as 10 ps for $3 \mathrm{~V}$ reverse bias. The induced index change depends strongly on the lifetime, as documented in Fig. 1 (bottom), which shows the effect of lowering the lifetime from 200 ps (as used in Fig. 1, top) to 20 ps. The relatively small measured $\Delta n_{g}$ is thus well explained by the short lifetime, which, on the other hand, implies a bandwidth of several $\mathrm{GHz}$, to be compared to the $\mathrm{kHz}$ range in [2]. Furthermore, the experimental observation of an optimum reverse voltage can be explained by the reverse bias dependence of the lifetime.

The scaling of the group index change with carrier lifetime has important consequences for the applications and will be further discussed at the conference.
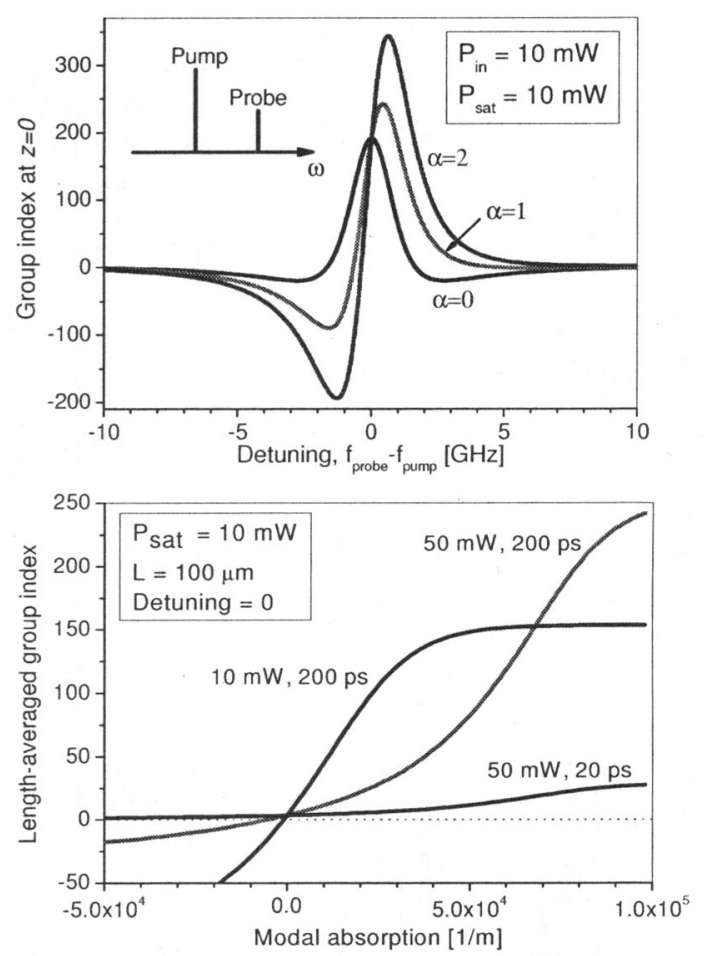

Fig. 1. Calculated variation of group index with detuning (top; at waveguide input for an absorption coefficient of $5 \cdot 10^{4} \mathrm{~m}^{-1}$ ) and modal absorption (bottom; averaged over waveguide length).

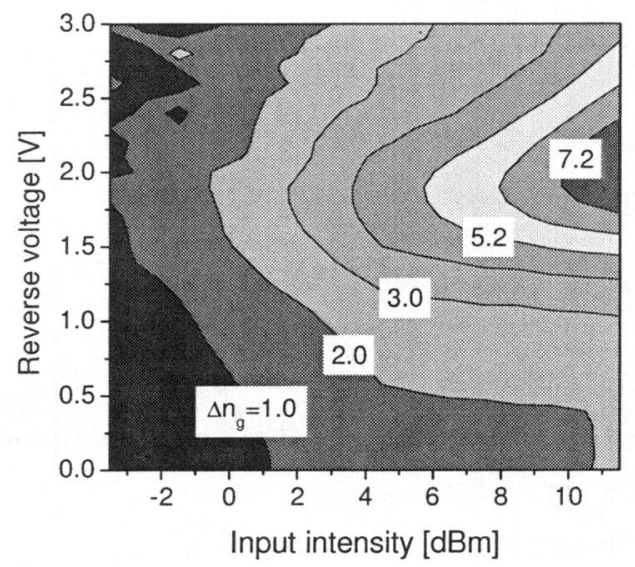

Fig. 2. Contour plot of measured change in group index versus input intensity and reverse voltage for a 100 $\mu \mathrm{m}$ long semiconductor waveguide.

[1] C. J. Chang-Hasnain et al., Proc. IEEE, vol. 91, pp. 1884-1897 (2003).

[2] M. Bigelow et al., Science, vol. 301, pp. 200-202 (2003). 